Goldschmidt 2021 Abstract

https://doi.org/10.7185/gold2021.6528

\section{DIGIS and GEOROC 2.0: A Project towards Open Geochemical Data}

\author{
MARTHE KLÖCKING ${ }^{1,2}$, BÄRBEL SARBAS ${ }^{3}$, WOLFRAM \\ HORSTMANN $^{4}$, STEFAN MÖLLER ${ }^{5}$, JENS NIESCHULZE ${ }^{6}$, \\ CAROLINE SPORLEDER ${ }^{7}$, MATTHIAS WILLBOLD ${ }^{5}$ AND \\ GERHARD WÖRNER ${ }^{8}$ \\ ${ }^{1}$ Georg-August-Universität \\ ${ }^{2}$ Australian National University \\ ${ }^{3}$ Max-Planck Institute for Chemistry \\ ${ }^{4}$ Göttingen State and University Library \\ ${ }^{5}$ GZG Göttingen University \\ ${ }^{6}$ eResearch Alliance, Göttingen University \\ ${ }^{7}$ Institute of Computer Science \& Göttingen Centre for Digital \\ Humanities \\ ${ }^{8}$ University of Göttingen \\ Presenting Author: marthe.kloecking@cantab.net
}

As open access publishing and FAIR data principles (findable, accessible, interoperable, reusable) become the new standard, geochemical data archives must not get left behind. Free access to up-to-date, scientifically curated data archives that are efficiently connected to the international community are essential. GEOROC is a leading source of geochemical and isotopic datasets, is connected to the „Interdisciplinary Earth Data Alliance", and has facilitated thousands of peer-reviewed publications and new avenues of geochemical research. In the new Digital Geochemical Data Infrastructure (DIGIS) concept of GEOROC 2.0, our goal is to continue and enhance the existing data collection by generating a connected platform that meets future challenges of digital data-based research and provides advanced service to the community.

Our approach is to (1) realign GEOROC with current and future demands in digital geochemical research, especially regarding FAIR principles; and (2) identify, develop and recommend good-practice rules for the curation of physical samples linked to the GEOROC 2.0 platform. This includes an interoperable metadata model as well as metadata and data exchange via standardised application interfaces (APIs). "Digital geochemistry" not only involves archiving and structuring of geochemical data but also the development of new tools and methods of data analysis. Increasing the accessibility and easeof-use of open geochemical databases ensures applications in other research areas. For instance, global soil research depends on representative and global coverage of rock substrate analyses. Spectral remote sensing of planetary surfaces requires mineral and rock reference compositions on a planetary scale. Archaeological studies linking artefacts to their provenance are based on knowing the chemical and isotopic composition of potential sources. The DIGIS concept for GEOROC 2.0 includes open access to end-to-end text and data mining, integration of data DOIs, links to a geochemical sample storage system via the International GeoSample Number (IGSN), multi-way data harvesting capabilities as well as state-of-the-art connectivity to other databases. The scientific development of GEOROC 2.0 as well as the re-organisation of its IT infrastructure will allow the database to expand into a more diverse range of geochemical data and thus ensure continued open access to a FAIR database for future Earth science research. 